\title{
Cidade e Imagens: memória coletiva na cultura urbana contemporânea na forma de coleções etnográficas em novas tecnologias
}

\section{Collective memory in contemporary urban culture in the form of ethnographic collections in new technologies}

Resumo: Este artigo refere-se a experiência desenvolvida pelos pesquisadores do Banco de Imagens e Efeitos Visuais (BIEV). Trazemos o estudo da pesquisa antropológica em novas tecnologias. Trata-se de formas mais integrativas, criativas e interativas voltadas a dinamizar a organização de coleções etnográficas junto ao mundo cultural urbano contemporâneo a partir dos diferentes suportes da fotografia, vídeos, textos e sons. A construção de tais experimentações etnográficas em novas tecnologias promove uma rede de informações e circulação de conhecimento a partir das formas de textualidade não lineares, que possibilitam uma perspectiva crítica da produção escrita antropológica no mundo contemporâneo.

Palavras-chave: Memória. Etnografia. Cidade. Cultura urbana. Fotografia. Vídeo. Texto. Som. Novas tecnologias.

Abstract: This article concerns on one hand, the experience carry on by the researchers of the Banco de Imagens e Efeitos Visuais (BIEV), and how the anthropogical research is transformed by the use of electronic media and the Web. We present a study about the integrative, creative and interactive dimensions in the organization of ethnographic collections about contemporary urban heritage, using photos, videos, texts and sounds. The launching of such multimedia ethnographic experiments, setting information in the web and based on non-linear textuality, draws new questions concerning anthropological practice in contemporary world.

Keywords: Memory. Ethnography. City. Urban culture. Photos. Videos. Texts. Sounds. New technology. nea na forma de coleções etnográficas em novas tecnologias. Informática na Educação: teoria \& prática, Porto Alegre, v. 11, n. 2, p. 9-23, jul./dez. 2008.

\author{
Cornelia Eckert \\ Universidade Federal do Rio Grande do Sul
}

\section{Ana Luiza Carvalho da Rocha \\ Universidade Federal do Rio Grande do Sul}

\section{Ponto de Partida}

A pesquisa no Banco de Imagens e Efeitos Visuais $(B I E V)^{1}$, ligado ao Laboratório de Antropologia Social/UFRGS, reúne o acervo de documentos etnográficos antigos e recentes sobre as transformações na paisagem urbana de Porto Alegre, na forma de uma base de dados digitais do Projeto Integrado Estudo Antropológico de Itinerários Urbanos, Memória Coletiva e Formas de Sociabilidade no Meio Urbano Contemporâneo, com financiamento do CNPq e FAPERGS (1997-2004).

O tema que reúne os pesquisadores e bolsistas do BIEV é o estudo antropológico da experiência temporal no mundo urbano contemporâneo, suas modalidades narrativas e as suas repercussões nas práticas e saberes que os indivíduos e/ou grupos constroem em suas relações com a cidade. Através deste eixo temático todos os pesquisadores que atuam no BIEV estão vinculados ao Núcleo de Pesquisa sobre Culturas Contemporâneas, do Programa de Pós-Graduação em Antropologia Social/ UFRGS.

${ }^{1}$ Disponível em: <http://www.biev.ufrgs.br> 


\section{Contextualização}

O BIEV foi criado pelas coordenadoras em 1997 no âmbito do Laboratório de Antropologia Social (PPGAS, UFRGS). Trata-se de um projeto que segue esquemas enunciativos oriundos dos domínios da Antropologia Urbana e da Antropologia Sonora e Visual. Objetiva ser um espaço de divulgação e de acesso aos usuários das redes mundiais de computadores aos conjuntos documentais versando sobre os acontecimentos vividos por grupos e/ou indivíduos em Porto Alegre, RS. Esta documentação resulta das pesquisas etnográficas realizadas por seus pesquisadores e bolsistas. Investese assim, na construção de "[...] comunidades interpretativas [...]" (RABINOW, 1999, p. 92) no que se refere à apropriação das representações acerca da estética urbana, da memória coletiva e do patrimônio etnológico local.

o que se coloca é a relevância de se contribuir para uma reflexão a respeito das diferentes formas expressivas adotadas pelas tecnologias de pensamento (oralidade, escrita, fotografia, vídeos, redes digitais) no mundo urbano contemporâneo, numa intenção interpretativa do conhecimento da matéria do tempo e de suas cadeias operatórias geradas no interior das sociedades complexas.

No BIEV a pesquisa experimental com as novas tecnologias esta orientada para a (1) a criação de um banco de conhecimento sobre memória coletiva e o patrimônio etnológico de Porto Alegre (BIEV-data), e a (2) sua divulgação (BIEV-site), a partir do portal Banco de Imagens e Efeitos Visuais.

O processo de construção de narrativas a partir das novas tecnologias da informática concebe o estudo de formas de indexação, de catalogação e de cadastramento dos conjuntos documentais etnográficos, em arquivos máster, nas bases de dados dos grupos de trabalho.

\section{Configuração dos Procedimentos de Trabalho}

As pesquisas no interior do BIEV constituemse a partir da existência de quatro grupos de trabalho segundo as linguagens adotadas para a pesquisa etnográfica na área da antropologia das sociedades complexas: vídeo,

\section{BIEV DATA}
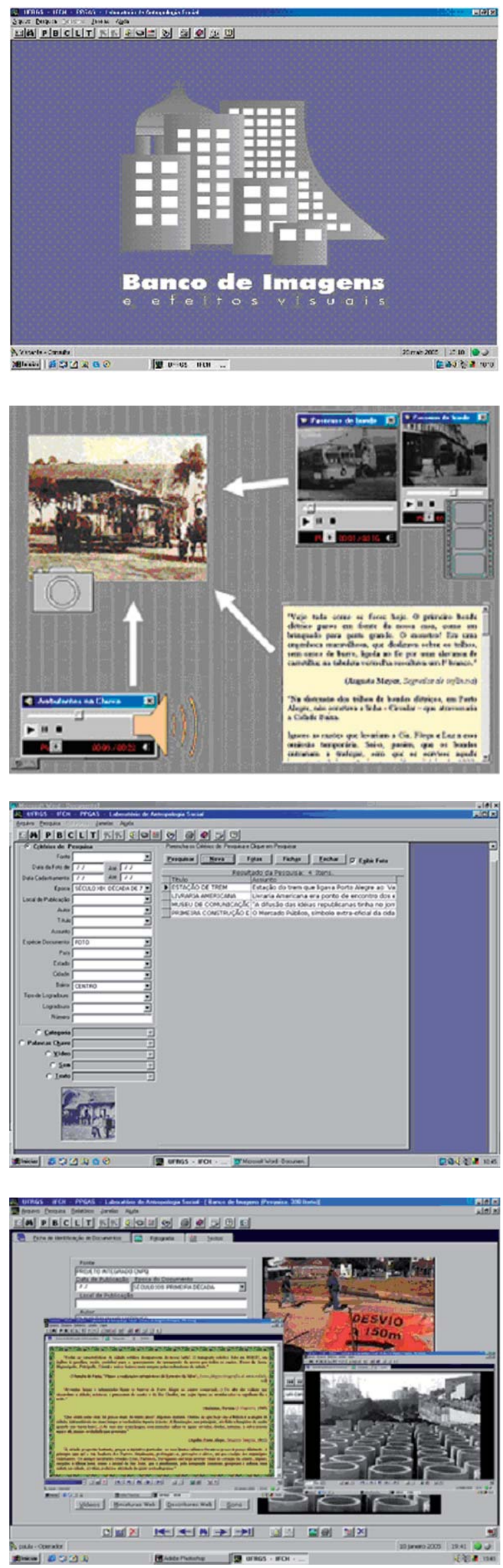

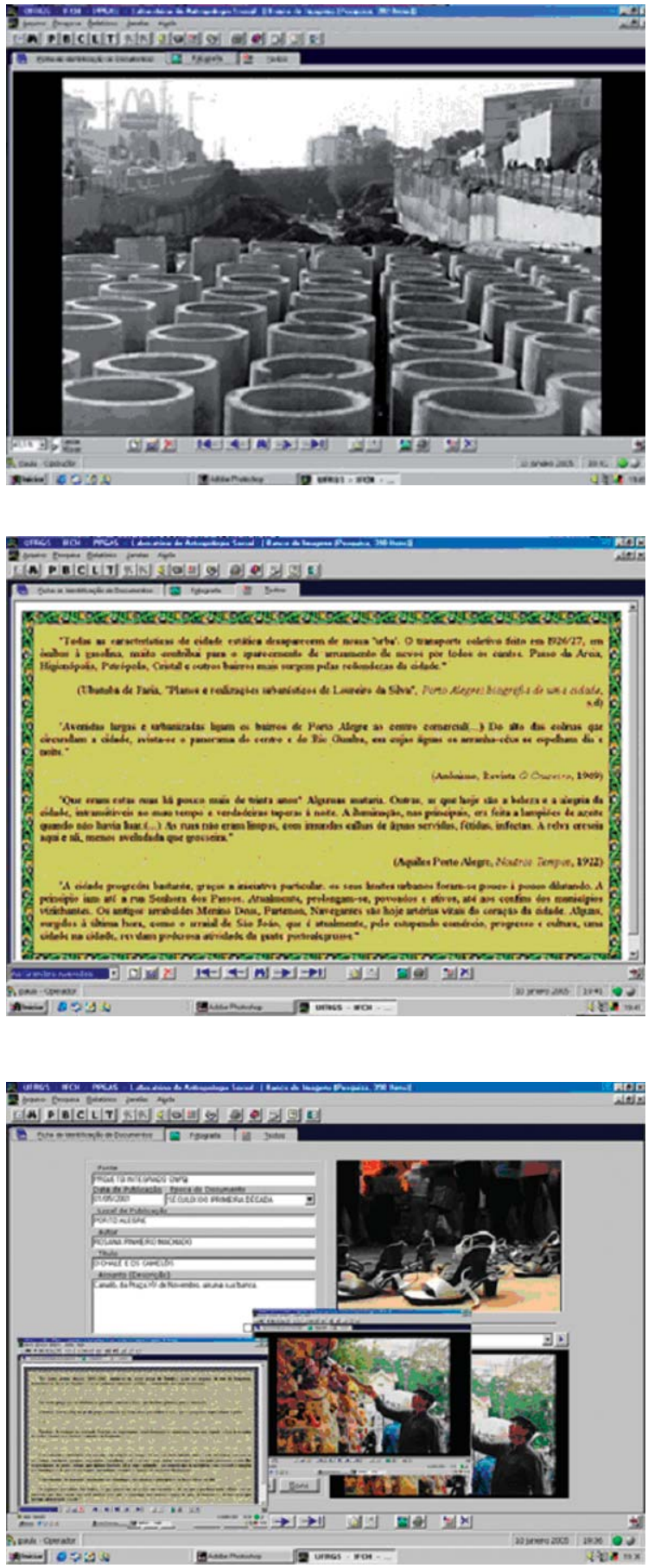

som, fotografia, escrita. Cada um dos grupos de trabalho $(\mathrm{GT})^{2}$ funciona através fóruns de discussões (ateliês de pesquisa metodológica) onde são discutidas as questões teóricas e conceituais relacionadas a prática do trabaIho de campo de cada pesquisador através do uso dos recursos audiovisuais. Os pesquisadores são doutores, doutorandos, mestres e mestrandos em antropologia, estudantes de graduação com bolsa de iniciação científica ou voluntária, sob a coordenação e orientação das autoras. Cada um dos GTs possui sob a sua guarda uma base de dados digitais das pesquisas etnográficas por eles realizadas (são considerados os arquivos máster) e onde cada um dos pesquisadores e dos bolsistas, após análise do material obtido em campo, deve cadastrar e indexar seus conjuntos de documentos.

Para que os conjuntos de documentos possam ser registrados em cada uma das suas bases de dados, os pesquisadores e bolsistas necessitam construí-los previamente na forma de coleções etnográficas. Esta atividade é realizada na medida em que avançam nos exercícios etnográficos em seus estudos de antropologia. Para orientar os registros dos conjuntos documentais nas quatro bases de dados, todos os pesquisadores e bolsistas do BIEV devem seguir as orientações contidas em Manuais de Orientação elaborados especificamente por cada um dos Grupos de Trabalho ao longo dos mais de 10 anos de desenvolvimento do projeto BIEV.

\section{As Coleções Etnográficas e o Método de Convergência: alguns apontamentos}

No desdobramento das pesquisas do BIEV nos territórios da vida urbana porto-alegrense, cada pesquisador e/ou bolsista ao construir suas coleções etnográficas necessita constituir conjuntos de documentos, dados e informações contidas em mais de um suporte que aquele ao grupo de trabalho ao qual pertence.

Geralmente, os pesquisadores e bolsistas são desafiados a explorar as fontes escritas e as fontes fotográficas (antigas ou recentes) como as primeiras linguagens na pesquisa de

2 São eles: GT de etnografia sonora, GT de fotografia, GT de vídeoetnografia e, finalmente, o GT de etnografia da escrita. 


\section{BIEV SITE}
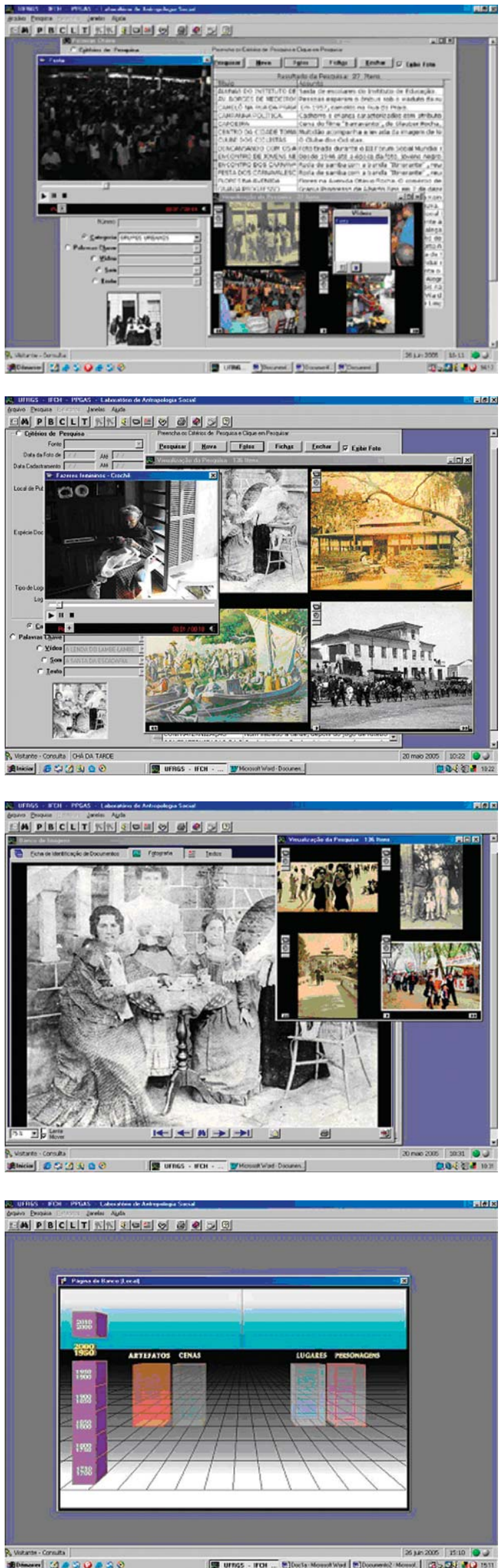

campo, adotando progressivamente as outras linguagens (vídeo e som) para a produção de conjuntos de documentos etnográficos. Tendo em vista que o eixo temático da pesquisa no BIEV trata da memória coletiva e do patrimônio etnológico no mundo contemporâneo, são as fontes escritas e fontes audiovisuais (principalmente a fotografia) que compõem os acervos documentais em museus, arquivos históricos, bibliotecas, centros de documentação aquelas que têm orientado a primeira etapa de imersão dos pesquisadores e bolsistas na produção documental sobre Porto Alegre. $A$ isto se acresce o fato de que é no interior deste patrimônio de imagens da comunidade urbana local que a sua própria produção etnográfica sobre o mundo contemporâneo porto alegrense deverá se situar.

O sistema de classificação dos documentos realizado por cada pesquisador ou bolsista no interior de conjuntos organizados (coleções) obedece ao sistema de categorias que configuram o campo conceitual da pesquisa no BIEV. Tais categorias conformam uma espécie de thesaurus, um dicionário hierarquizado segundo um vocabulário característico do campo de pesquisa do BIEV e dos seus termos genéricos e específicos em termos de domínio no âmbito dos estudos antropológicos em sociedades complexas.

Por serem constituídas como invariantes operatórias (VERGNAUD, 2007) para a interpretação de documentos cujas fontes podem ser escritas ou audiovisuais, tais categorias formam um conjunto estruturado de termos escolhidos segundo sua capacidade descritiva do documento etnográfico no sentido de possibilitar o acesso aos seus usuários tanto quanto tratar a informação nele contida. Os termos do thesaurus estão organizados hierarquicamente e é esta hierarquia que permite aos pesquisadores e bolsista obter certa precisão na indexação de seus conjuntos documentais segundo suas interrogações específicas de pesquisa ${ }^{3}$.

As categorias adotadas foram, portanto, um instrumento de indexação, e guiadas pelo

${ }^{3}$ Tendo em vista uma adequação das categorias, palavras-chaves e descritores no interior do domínio específico da pesquisa do BIEV, as categorias e palavras-chaves inventariadas precisam ser comparadas, colocadas em relação entre si e finalmente hierarquizadas para dar conta dos temas de pesquisas desenvolvidos por seus pesquisadores e bolsistas. Esta hierarquia se apóia numa tipologia uma vez que cada termo pertence a uma categoria que se situa em relação à outra categoria. 

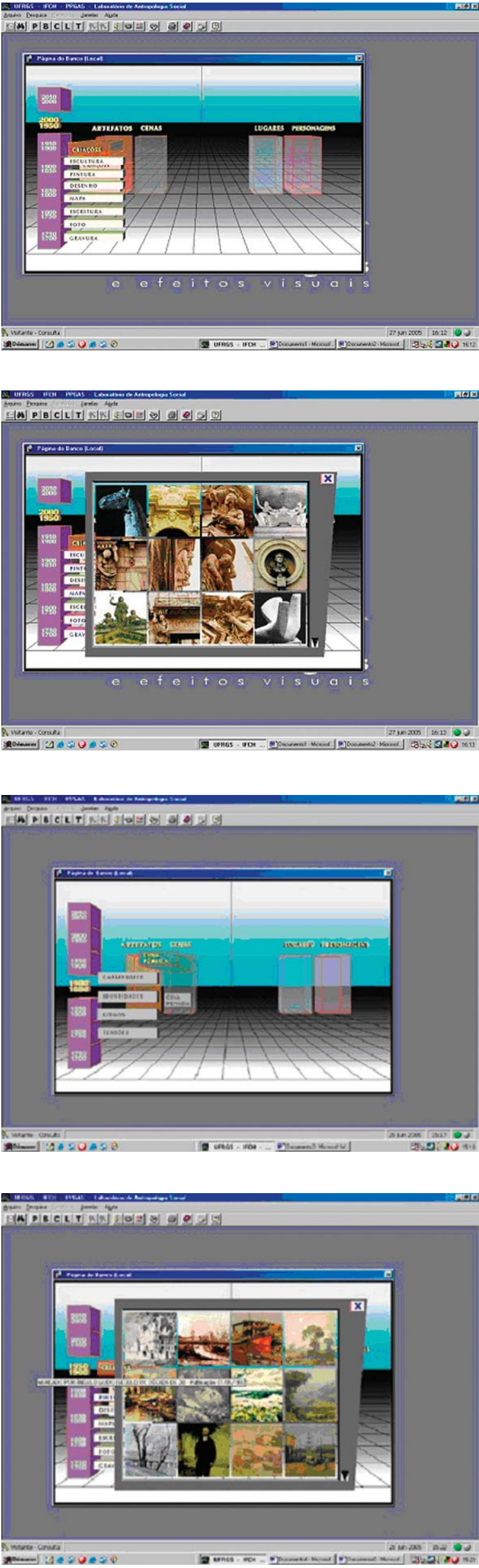

thesaurus é possível representar, assim, os documentos etnográficos em conjuntos ordenados segundo uma seleção de palavras denominadas de palavras-chaves, assegurando-Ihes uma forma específica de gestão documental.

Uma vez que tais categorias estão referidas a área de concentração da pesquisa com estética urbana, memória coletiva, cotidiano, trajetórias sociais, narrativas biográficas, formas de sociabilidade e itinerários urbanos no mundo contemporâneo, criam-se em torno delas e palavras-chaves núcleos semânticos organizadores de imagens (seguindo-se aqui o método de convergência adotado por Gilbert Durand (1980), tendo por base o isomorfismo das imagens (ROCHA, 2008), e para as quais se podem associar um número limitado de palavras-chaves além de descritores ${ }^{4}$.

Durante o processo de indexação dos conjuntos documentais nas bases de dados de cada um dos GTs cada pesquisador do BIEV é desafiado a realizar a montagem de suas coleções e, posteriormente, na escolha de certos conjuntos documentais processarem o seu cadastramento no banco de dados do BIEV, sendo o material também preparado para ser disponibilizado em internet. A base de dados é então denominada de BIEV-data é onde estão reunidos os conjuntos documentais de todas as pesquisas realizadas, na forma de arquivos máster, os quais são preparados para serem disponibilizados para a WEB. Cabe aqui informar que a base de dados do BIEV adota o ACCESS como software de armazenamento e - VISUAL BASIC para a interface de consulta do usuário. Na Internet fez-se uso do sistema ACESS VISUAL BASIC. Ambos os sistemas atualmente estão sendo alterados pela decisão de migrar o BIEV para o sistema LINUX de software livre.

\section{A Antropologia das Sociedades Complexas e as "Textualidades" Eletrônicas}

${ }^{4} \mathrm{Em}$ termos das estruturas figurativas que as imagens contemplam, para a arqueologia antropológica de Gilbert Durand, trata-se de construir uma classificação de símbolos os quais constelam em torno de um mesmo tema arquetipal, segundo a equivalência de suas formas (equivalência morfológica), ou seja, das imagens cuja materialidade dos seus elementos se parecem. Neste ponto o autor esclarece sua distância do estruturalismo levistraussiano, pois não se trata de uma convergência de imagens por analogia (equivalência funcional), ou seja, de acordo que a função que uniria a materialidade dos elementos de imagens diversas (ROCHA, 2008). 

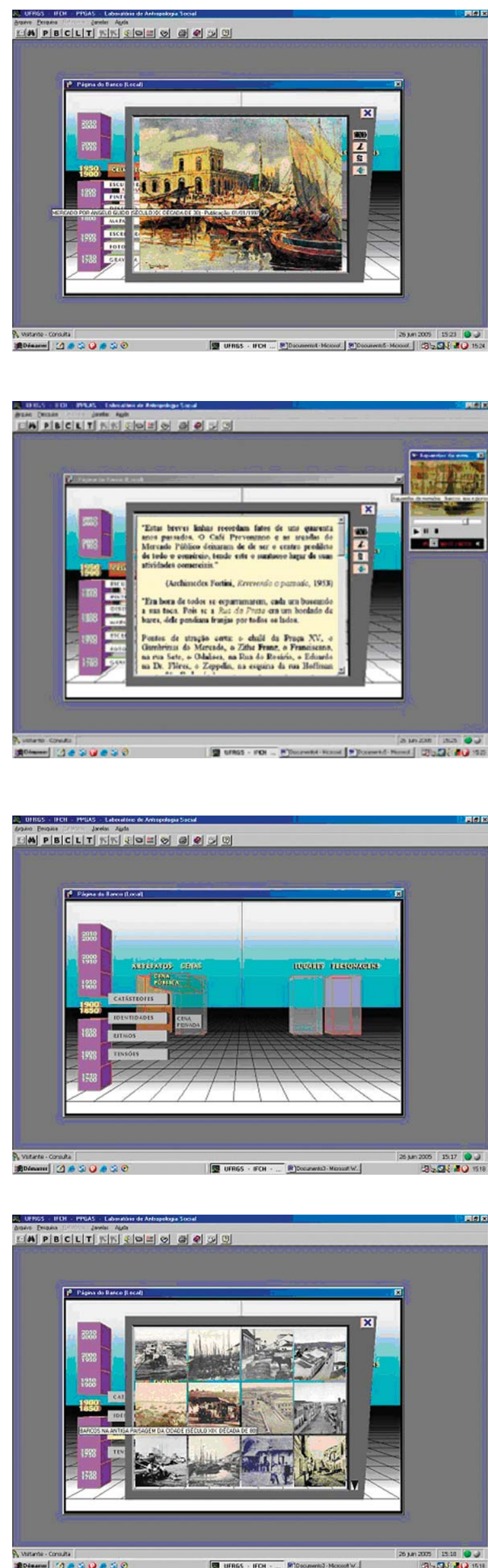

A Antropologia desde seus primórdios vem incorporando mapas, gráficos, fórmulas matemáticas até a fotografia, o filme e o gravador como forma de registro e exposição dos dados de campo tanto quanto forma de comunicação de suas etnografias. Mais recentemente as novas tecnologias foram incorporadas às outras formas de registro e exposição de dados etnográficos reunidos nas pesquisas de campo pelos antropólogos.

Ao consideramos que o uso das novas tecnologias digitais e eletrônicas na pesquisa antropológica assim como a divulgação de estudos etnográficos em web-site nas redes mundiais de computadores, pela ambigüidade característica da representação digital e eletrônica, nos provoca a pensar o processo de leitura e escrita da representação etnográfica clássica em termos de sua natureza e forma.

Ler um texto etnográfico, portanto, na sua forma de um objeto impresso significa obediência a sua forma de argumentação submetida à seqüência espacial da paginação das folhas, seguindo-se uma ordem temporal determinada, e através da qual o autor da obra procura restaurar para seu leitor os fatos e as situações por ele vividos em campo. Diferente de ler um livro, a leitura de uma etnografia tendo como suporte as tecnologias da informática se converte numa ação de busca onde o leitornavegador não consegue jamais ver globalmente todo o conjunto de dados documentais, tendo dele apenas uma visão local.

\section{A Cidade como Objeto Temporal}

Como sugere cada vez mais a análise compreensiva dos fenômenos da memória e do patrimônio no mundo contemporâneo que vimos desenvolvendo, o tempo torna-se humano na medida em que está articulado de forma narrativa e que as ações, situações, acontecimentos vividos esboçam traços da experiência temporal humana 5 .

O uso das tecnologias da informática, com o tratamento eletrônico ou digital da memória, neste sentido, torna-se interessante tema de pesquisa e investigação ao permitir explorar a fruição estética do tempo como realida-

5 Ver o respeito: ECKERT, C.; ROCHA, A.L.C. A Cidade e o Tempo. Porto Alegre, Ed. da UFRGS, 2006. 

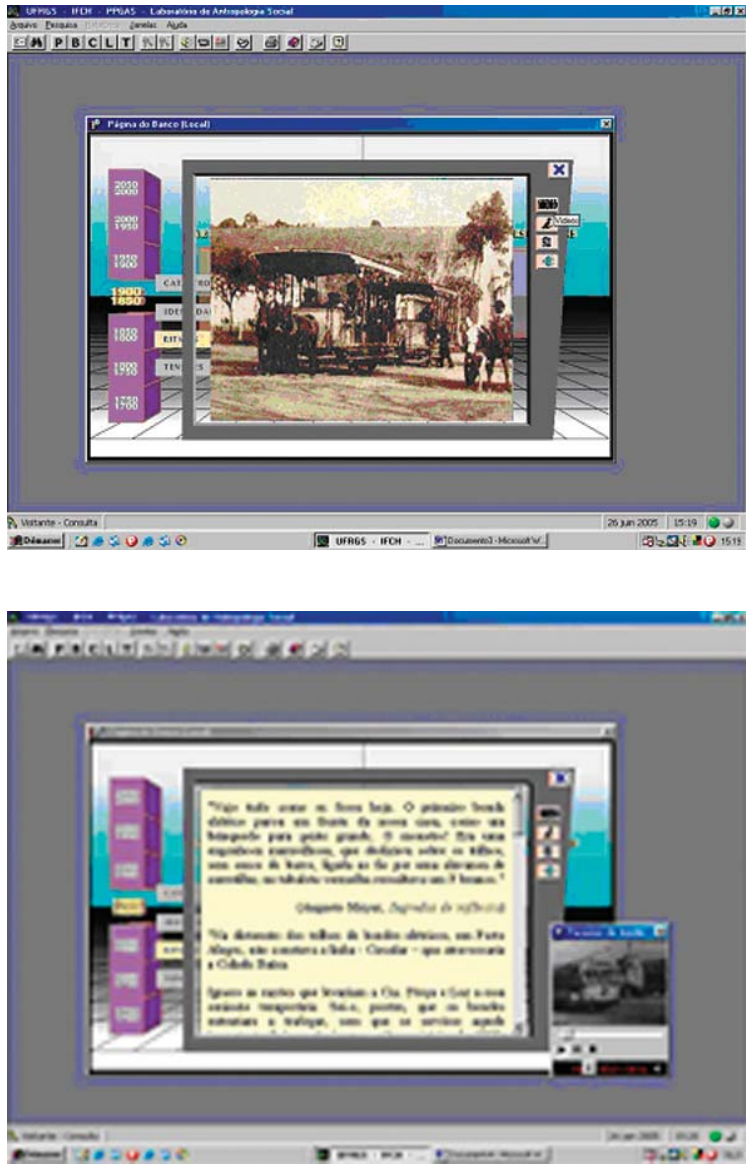

de composta de um continuum de instantes logicamente hierarquizados (BACHELARD, 1987), e não como simples monumentos de lembranças.

O uso de formas mais integrativas e interativas de resgate, recuperação, criação e produção de coleções etnográficas sobre as transformações da paisagem urbana no mundo contemporâneo, no caso do BIEV, abarca o estudo de dois utensílios interpretativos específicos para a restauração da totalidade desta paisagem como patrimônio etnológico, através dos jogos da memória de seus habitantes. As cidades contemporâneas como obras coletivas podem ser entendidas como obras-pormenor e/ou obras-fragmento, considerando-se dois tipos de divisibilidade de sua paisagem: o corte e a ruptura.

\section{Cortes e Rupturas: o jogo da parte e do todo}

Cortes e rupturas têm sido tratados, na configuração do sistema de consulta e gerenciamento da base de dados do BIEV, elementos indutores de narrativas etnográficas do e no meio urbano de Porto Alegre uma vez que, através de ambas as ações, os usuários exploram o conhecimento local do fenômeno do desencaixe do tempo e do espaço que caracteriza a configuração das modernas sociedades complexas.

Valemo-nos aqui dos estudos seminais de Calabrese (1987) sobre a situação cultural neobarroca onde ocorre a celebração do fragmento, do nó e do labirinto como qualificativo das formas de pensar contemporâneas e que tem sido largamente empregado no BIEV para o estudo das formas informes que presidem a estética urbana e a memória coletiva das cidades tropicais, sob os efeitos da agitação temporal 6 .

Corte e ruptura são modalidades interpretativas dos fluxos das imagens que impedem que os conjuntos de documentos pertencentes às coleções etnográficas, reunidas no interior dos acervos de imagens digitais do BIEV, sirvam apenas como depósitos ordenados de

6 Conforme tese de doutorado: Rocha, A.L.C. Les sanctuaire du désordre, ou art de savoir-vivre des doux barbares sous les Tristes Tropiques. Orientação de M. Maffesoli. Sorbonne : Université René Descartes, 1994. 
uma cultura material. Corte e ruptura, orientam diferentes jogos de leitura/interpretação do objeto-cidade no sentido de confrontá-lo com as ordens discursivas históricas, lineares e progressistas acerca das transformações dos cenários da vida coletiva em Porto Alegre.

\section{Corte}

Através do corte as paisagens urbanas podem ser talhadas e retalhadas desde sua totalidade integral de origem. Através do corte o usuário é obrigado a pensar a paisagem urbana de uma cidade por inteiro, sua textura, sua consistência como totalidade orgânica.

O corte conduz um detalhe da paisagem urbana à totalidade da cidade. O corte permite reler uma totalidade em pormenor (detalhe). O uso do corte supõe as paisagens urbanas como sistema dotado de um significado global. A função do corte é compreender as transformações da cidade desde a reconstrução de suas porções no interior de conjunto.

o corte permite a descoberta das leis que a ordenam como paisagem urbana (Exemplo: o uso da lupa para realizar o zoom em uma fotografia de acervo, o uso do zoom numa montagem em vídeo de uma fotografia ou o uso do slow na produção de uma crônica videográfica ${ }^{7}$ etc.). O corte é uma ação que se concretiza o pormenor como recurso interpretativo

\section{A Ruptura}

Através da ruptura as paisagens urbanas são apropriadas desde seu caráter fractal ou de fratura e do rompimento com a sua totalidade de origem. O inteiro da paisagem esta ausente. Pela via do fragmento as paisagens urbanas só podem ser reconstruídas por suposição, indiretamente, por estar referida a interrupção de seus supostos sistemas de pertença, pois sua integralidade se apresenta como lacuna.

Através da ruptura, o usuário do acervo digital do BIEV vale-se de um modelo conjuntural desde onde uma porção de paisagem urbana é analisada como objeto indiciador (índice) do seu inteiro, destruído pelo tempo. (Exemplo: a fotografia de uma fachada de sobrado colonial

7 Conforme termo cunhado por Rafael Devos, da equipe de pesquisadores do GT de vídeo (BIEV, 2005). no interior de uma avenida; uma seqüência em vídeo de uma porção de calçamento antigo com a presença de um pedaço de trilho de bonde etc.).

\section{Pormenor (Corte) e o Fragmento (Ruptura)}

Tomando-se a cidade, assim, enquanto obra coletiva baseada no comportamento estético e na personalidade étnica de uma comunidade de destino, a pesquisa em torno de novos experimentos etnográficos, com base nas tecnologias digitais e eletrônicas, tem nos permitido explorar melhor os critérios de pertinência do uso do Pormenor ou do Fragmento como fonte interpretativa dos jogos da memória de seus habitantes e como ato configurador de paisagens urbanas ${ }^{8}$.

\subsection{O Pormenor}

Pensar a estética do pormenor (o detalhe) no tratamento das paisagens urbanas nos permite considerar os pequenos detalhes da cidade possam ser extraídos e analisados, compreendendo-se os estilos diferentes do viver urbano.

Com a estratégia de se operar com o detalhe nas paisagens urbanas em transformação atingimos a possibilidade de descobrir na regularidade das paisagens urbanas algo excepcional, colocando-as em relevo suas particularidades.

No âmbito dos jogos da memória, a lógica do pormenor numa tela-janela de consulta permite ao usuário, por exemplo, observar as paisagens urbanas em suas porções, segundo uma aproximação ao particular que as caracterizam, analisado desde sua regularidade, isto é, sua estrutura.

\footnotetext{
${ }^{8}$ As expressões comportamento estético e personalidade étnica são inspiradas nos usos que delas fez ROCHA (1994) em sua tese de doutorado acima citada. Trata-se de expressões cunhadas por A. LEROI-GOUHRAN e através das quais o autor analisa o relativismo das qualidades estéticas que transparecem do encontro entre função e forma nos estudos dos objetos e instrumentos arqueológicos das diferentes sociedades humanas. Na referida tese, a autora emprega os termos no sentido de pensar as estéticas urbanas das cidades apenas associada ao grau das técnicas ou das tecnologias, mas associadas às origens de uma cultura (e de seu passado étnico), pensando-a como expressão da personalidade de seus habitantes e dos seus valores estéticos.
} 


\subsection{O Fragmento}

Explorando-se a idéia de fragmentos reais do passado na interpretação de uma paisagem urbana, busca-se o regresso de uma parte da cidade a sua totalidade de origem através dos jogos da memória de um tempo e de um espaço.

Pensar a estética do fragmento, do ponto de vista formal das telas de consulta implica na apresentação das transformações nas formas de vida social em Porto Alegre sob a ótica de intervalos de espaço-tempo arqueológicos, sendo através deles que uma comunidade urbana se configura como tal.

Com a estratégia de se trabalhar o fragmento nas paisagens urbanas o processo de destruição e reconstrução da cidade, a singularidade específica de um fragmento necessita voltar para a normalidade de seu sistema de origem, de que o fragmento faz parte.

\subsection{BIEV-data: o jogo entre pormenor e o fragmento}

No caso do BIEV-data, a interface de consulta das formas das paisagens urbanas de uma cidade proposta para o usuário lhe permite escolher algumas de relações possíveis entre os conjuntos de documentos ordenados e dispostos segundo um thesaurus (categorias, palavras-chaves e descritores, isoladamente ou por associação). Porém, o acesso às coleções adota a forma de laços tipificados segundo a indexação das formas de tratamento espaço-temporal para o fenômeno da memória coletiva que elas permitem (oposição, contigüidade, continuidade etc.).

Dentro destes parâmetros e convenções, diante da linearização que as fontes escritas e audiovisuais oferecem a consulta ao BIEVdata tanto quanto BIEV-site se processam de forma aleatória, favorecendo uma estética da desorientação que interessa para o caso da pesquisa laboratorial com novas tecnologias digitais e eletrônicas aplicadas ao estudo da pluralidade temporal da memória coletiva e do patrimônio etnológico no mundo urbano contemporâneo.

\subsection{BIEV-site: o fragmento como acesso ao pormenor}

Seguindo-se Calabrese (1987), o fragmento atua no plano narrativo de uma operação temporal de micro-histórias ou de camadas arqueológicas, visando restaurar na consciência do leitor-navegador a cidade como duração, ou seja, dos seus resíduos como condição interpretativa de uma obra moldada e configurada pelo depósito de muitos gestos e intenções dos grupos humanos que nela habitaram. O fenômeno da eterna destruição e reconstrução dos territórios da vida urbana porto-alegrense pode ser visto, aqui, sob a ótica da forma como os habitantes renovam o seu passado urbano, através de um lento processo de destruição criativa como luta pela sua continuidade temporal.

\subsection{O Fragmento, o Pormenor e a Destruição Criativa das Cidades}

Inspirados nas inquietações bachelardianas e piagetianas, e adotando-as para revisitar os estudos sobre memória nos termos empregados pela matriz antropológica ${ }^{9}$, temos por centro de preocupações a realização de etnografias da duração (ECKERT; ROCHA, 2000) e seus cronotropismos (ROCHA, 1993), ou seja, a etnografia dos diversos ritmos que configuram uma comunidade urbana como tal e a descrição dos arranjos da vida coletiva que se propaga no interior de seus territórios.

A proposta é, então, como etnógrafo colocar-se ao lado da riqueza temporal da cidade moderno-contemporânea materializada na cadência dos gestos e intenções de seus habitantes, para desde aí narrar a propagação de sua matéria através da construção de coleções de documentos etnográficos sobre Porto Alegre. Esta proposta de investigação da cidade desde os seus ritmos temporais, resultado da acomodação de instantes descontínuos vividos por seus habitantes se afasta da idéia (bergsoniana) da duração como realidade imediata de um ritmo único, de um tempo histórico, linear e progressivo, segundo a sua periodização num tempo vazio para o tratamento espacial da memória. Ou seja, as utopias urbanas do passado funcionam na

${ }^{9}$ Conforme expressão cunhada por Roberto Cardoso de Oliveira (1988). 
condição de espécies de depósito de formas e conteúdos esparsos através dos quais os habitantes da cidade relacionam-se com as suas vivências contemporâneas.

Em se tratando da pesquisa com uma estética urbana pautada por ritmos diferentes, medida pelos graus de tensão ou relaxamento dos seus habitantes diante da experiência da rapidez ou da lentidão do tempo em seus territórios, se atinge a etnografia da duração através do estudo desta elasticidade temporal e suas modalidades narrativas. Uma distentio temporal cuja trama da experiência vivida de seus habitantes, tece para as cidades brasileiras um tempo suficientemente regular para lhes assegurar uma impressão de continuidade.

Considerando-se assim a tese bachelardiana (1987) da multiplicidade de durações (fenômeno reconhecido também por Bérgson) trata-se de pensar o mundo urbano-contemporâneo, em particular no caso das cidades brasileiras, desde a ótica das distopias do passado como matéria privilegiada de análise de seu patrimônio etnológico. O que se pode observar no Brasil é, então, que a cidade-ruína pode ser pensada como a expressão do conjunto de intenções e de comportamentos de uma comunidade urbana diante do tempo.

\section{Alguns Aspectos da Pesquisa Metodológica}

Os cronotropismos bachelardianos das cidades brasileiras nos desafiam a pensá-las desde os tempos vividos dos seus habitantes em suas tensões com o tempo progressista e histórico do mundo. Explorando-se tais condições temporais na leitura das condições espaciais nas quais vivem os habitantes das grandes cidades do Brasil é que enveredamos para uma pesquisa com etnografia hipertextual - forma adotada para etno-grafar a vida das formas urbanas no contexto de uma rítmica temporal de sua leitura plural e múltipla.

\section{Por uma Etnografia Hipertextual}

Denominamos de etnografia hipertextual ${ }^{10}$ a um conjunto não estruturado a priori de infor-

${ }^{10}$ Conforme expressão cunhada por Ana Luiza Carvalho da Rocha (2006) mações e dados colhidos pelo antropólogo em seu trabalho de campo, em suportes diversos (textos, fotos, filmes) e que, digitalizados (e ligados entre si por nós ou laços) são colocados num mesmo ambiente de consulta conformando um processo de interpretação de culturas, segundo um sistema aberto, onde a leitura de um dado imediatamente re-configura a totalidade do universo etnográfico do qual faz parte.

No caso dos bancos de dados do Banco de Imagens e Efeitos Visuais (assim como das bases de dados de arquivos máster dos GTs), este aspecto se torna evidente no caso da representação das paisagens urbanas que conforma o patrimônio etnológico da cidade de Porto Alegre. Para o acesso aos conjuntos documentais que configuram as coleções etnográficas sobre a cidade seja através do banco de dados (BIEV-data), seja pela (BIEV-site), o leitor-navegador é sempre conduzido a um dispositivo de leitura criado por um programa/ferramenta especialmente para esta finalidade, e onde a totalidade dos documentos se encontra articulados entre si através de um thesaurus.

Num tal dispositivo, as interfaces criadas para a tela de consulta não pode ser pensada aqui como prolongamento das páginas de um livro, ainda que este efeito possa ser possível de ser explorado como fruição estética na modalidade de leitura de um livro virtual. Num hipertexto, o dispositivo de leitura ocorre conforme a continuidade temporal que orientam os jogos de enquadramentos e sobreposições de telas-janelas usados pelo leitor-navegador. Através desses jogos de destruição como condições de dispositivos enunciativos, as informações e dados etnográficos se tornam acessíveis segundo um determinado fluxo de imagens e as suas ressonâncias na consciência do leitor-navegador.

Apesar da estrutura da navegação (os laços profundos e os laços automáticos) estar a priori ordenada segundo uma linguagem de programação (aliás, como toda a linguagem humana, ou seja, não pretendemos que as novas tecnologias não disponham de tais estruturas da linguagem como outra qualquer, muito pelo contrário), fica evidente em um hipertexto quem define o percurso das escolhas é aquele que consulta a base de dados, logo, o leitor-navegador (laços ativáveis) engalfinhado numa cadeia de ações de destruição de la- 
ços semânticos entre os documentos, os quais só podem ser restituídos por sua solicitação direta.

\section{Do Fragmento e do Pormenor à Montagem de Coleções Etnográficas}

No plano dos estudos de Antropologia visual e sonora do BIEV e de suas preocupações com a pesquisa com as descontinuidades temporais que conformam a memória coletiva e o patrimônio etnológico no mundo contemporâneo, temos operado sempre o desafio de reunir um conjunto amplo de imagens (sonoras, visuais, escritas, fotográficas) num mesmo ambiente de consulta. O desafio tem sido o de explorar a linguagem das novas tecnologias digitais e eletrônicas para a construção de coleções etnográficas, cujo fluxo de imagens consteladas em núcleos organizadores de sentido, nos permita narrar a cidade moderno-contemporânea desde o conhecimento acerca do fenômeno da duração que ali se apresenta.

Norteando-nos pelos princípios de uma etnografia da duração e o desafio de pensar a vida urbana porto-alegrense desde a continuidade formal que seu corpo coletivo adota em seus territórios, quanto mais constelações de imagens sobre o patrimônio etnológico dessa comunidade urbana os pesquisadores e bolsistas reunirem em suas coleções etnográficas tanto mais direções estes conjuntos documentais lhe permitirão construir conhecimento sobre a ordem de fenômenos que tais imagens carregam.

A pesquisa da memória coletiva a partir da produção e geração de coleções etnográficas resulta para o pesquisador, nos moldes adotados pelo BIEV, num denso processo de imersão nas motivações simbólicas imemoriais de uma comunidade urbana, o que torna evidente a pesquisa antropológica, nestes termos, participa de uma obra que integra o próprio patrimônio da humanidade. Pensar a cidade através de suas imagens por parte do pesquisador do BIEV comporta sempre adições, correções, subtrações e retoques em tais imagens que são o fruto da colaboração de todos aqueles que produziram tais documentos, no passado e/ou no presente.

\section{Método de Convergência e a Montagem das Coleções num Acervo Digital}

Pela ambigüidade fundamental que contempla toda a imagem é que as coleções são assim montadas e desmontadas. Seguem pois, as ordens dos fluxos de sentido que as suas formas tecem entre si, e é neste processo que situa o trabalho do antropólogo em seu esforço de compreender o semantismo dos símbolos que as configuram para desde aí indexá-las nas bases de dados do BIEV para, posteriormente, disponibilizá-la na Internet.

Formar coleções etnográficas para o caso de imagens de acervos produzidas fora ou dentro do BIEV, como resultado de uma etnografia da duração, significa ultrapassar a análise sociológica ou historiográfica dos símbolos geralmente compreendidos desde os momentos históricos em que são agenciados por uma comunidade urbana. Significa também superar a sua interpretação mediada pelas modalidades de trocas e relações sociais nas quais esses símbolos emergem, uma vez que o simbolismo das imagens escapa à consciência clara do corpo coletivo desde onde se originam.

Neste contexto intrigante onde criador (pesquisador) e criatura (as imagens) se reúnem como parte de um contexto interpretativo de ressonância de símbolos, o ato de formar coleções implica não só a compreensão lógica do fluxo das imagens, anônimo e présubjetivo, que as orientam, mas a adesão a esta experiência sensível do tempo inscrita na sua própria consciência. Espécie de lugar de narração (topos) onde se apresentam continuidades e sínteses impessoais, o tratamento metodológico que orienta a construção de coleções etnográficas, pela via da duração, nos moldes do pensamento bachelardiano, retoma alguns temas fortes por nós já enfrentados que é o da compreensão da dialética temporal que tece a solidariedade entre o tempo vivido (subjetivo, intransitivo, pensado) e o tempo do mundo (objetivo, concreto). 


\section{Diálogo com a Cultura do Espetáculo com a Memória Eletrônica e Digital}

No caso do BIEV, trabalhando há mais de 10 anos, com as tecnologias eletrônicas e digitais na pesquisa com a etnografia da duração, tal convergência de imagens reunida num mesmo sistema de consulta, imagens oriundas de fundos de origens diferentes (antigas e recentes, fabricadas ou não pelos antropólogos) e de fontes diversas (foto, vídeo, filme, pintura, escrita, som etc.), tem nos indicado, desde o ponto onde elas convergem, a direção mais próxima para a interpretação da dialética temporal que as presidem, desde suas origens até hoje.

Um aspecto interessante que temos ressaltado a partir da pesquisa com as novas tecnologias aplicadas ao estudo da dialética temporal que orienta os domínios da memória coletiva e do patrimônio etnológico no mundo contemporâneo é que as novas possibilidades de museologização, advindas da memória eletrônica e digital (e mediada pela conformação da tela do computador), conforme muitos autores já apontaram, nascem e se alimentam de velhas e antigas formas de registro documental das imagens do tempo, segundo seus diferentes suportes físicos - e muito especialmente a cultura da tela.

A tela dinâmica do computador se insere no curso da conformação de uma cultura visual singular às sociedades moderno-contemporâneas: a presença de uma informação visual numa tela retangular e plana, colocada numa certa distância do olho do observador, dandoIhe a ilusão de navegar virtualmente no espaço e no tempo. Ela vincula-se às formas usuais de registro documental do fenômeno espaço/ tempo que estão intimamente associadas, por seu torno, a conformação de uma sociedade do espetáculo.

Ou seja, o mundo de telas que nos fornecem as atuais redes digitais e eletrônicas nasce e floresce a sombra de uma indústria de entretenimento cada vez mais sofisticada, e continua a disponibilizar, como noutros tempos, o consumo cultural de formas representacionais associadas, agora, a idéia de complexos de informações e dados.

A produção dos efeitos de simulação e interatividade característicos da imagem digital e eletrônica é presidida pela obsessão da indústria da mídia e das tecnologias da informática com o ilusionismo visual da imagem digital, ou seja, sua capacidade de capturar, e mesmo ultrapassar, o naturalismo e realismo fotográfico e fílmico.

Apesar de se reconhecer que o advento do ilusionismo visual das novas tecnologias origina um novo tipo de interação entre o corpo do espectador e a imagem, no que tange ao tema da tela-interface no processo criação de museus virtuais e as formas de exposição de conjuntos de informações e dados, é importante ressaltar que se continua no interior das formas expressivas de uma cultura visual de cunho museológico.

\section{Obstáculos Epistemológicos e Desafios Antropológicos}

\subsection{O Tema do Direito de Uso de I magem e Som e de Propriedade I ntelectual}

Em especial, as novas tecnologias da informática no tratamento do patrimônio etnológico no mundo urbano contemporâneo embora possam estar, eventualmente, associada a uma dose de risco do ponto de vista da pesquisa antropológica mais clássica, vem avançado, no interior do BIEV, no sentido de delimitar as fronteiras entre a descrição de uma experiência etnográfica feita por antropólogos, e para antropólogos, daquelas destinadas ao uso coletivo de pessoas comuns, não pesquisadores.

Tendo em vista o desafio dos códigos de conduta que devem orientar as decisões de compartilhamento de documentos, informações e imagens antigas e recentes da cidade de Porto Alegre na WEB a partir das formas históricas de ação no mercado livre de software, o tema das normas éticas deve ser aqui prioritário.

Diante destes desafios de restauração da palavra do Outro, a emergência de uma etnografia hipertextual tem nos conduzido a refletir sobre os princípios éticos que orientam o saber-fazer antropológico tradicionalmente produzido na forma de objeto-livro quando ele é confrontado não somente aos desafios de se romper um discurso hegemônico sobre o Outro, orientado que está pela defesa da igual- 
dade dos grupos humanos na diferença, mas quando se projeta na rede mundial de computadores, na era das textualidades eletrônicas.

\subsection{A Aprendizagem da Escritura Etnográfica Através das Redes Digitais e Eletrônicas}

As interfaces homem-computador para se pensar a leitura das dinâmicas culturais contemporâneas despontam como novas possibilidades de exposição de conjuntos de documentos etnográficos sobre as paisagens urbanas ao se constituírem em janelas através das quais podemos acessar lugares, pessoas, acontecimentos e situações distantes tanto no espaço quanto no tempo e que sugerem novas formas possíveis de ver, olhar e interagir com as imagens do tempo.

$\mathrm{O}$ antigo conceito de imagem transmuta-se em imagem-interface ou imagem-instrumento. Clicar, zonear a imagem ao mesmo tempo em que tomar decisões ou selecionar, caracteriza-se por uma dinâmica temporal singular de apropriação da tela dinâmica que prevê a relação do usuário com os atos artificiais, incompletos e desconstrutivos da máquina do computador.

A lógica clássica das formas de exposição de conjuntos documentais se rompe se considerarmos que a consulta a uma base de dados impõe o leitor-navegador tipos diferentes de atos cognitivos: analisar diferentes conjuntos de informações: processar uma busca, iniciar suas aplicações, navegar através das páginas da tela, novamente iniciar outra busca, e assim sucessivamente, num mesmo tempo, através de múltiplas telas abertas, que vão Ihe exigir sempre novas perguntas e novas respostas.

No BIEV, a pesquisa antropológica em torno de formas mais integrativas, criativas e interativas de operar e recuperar a conjuntos documentais versando sobre o tema do patrimônio etnológico do mundo urbano contemporâneo, tem se tornado um espaço privilegiado de construção de novas narrativas etnográficas justamente porque através delas obtém-se uma importante chave de interpretação dos seus tempos e espaços sociais.

\subsection{O Instante Presente e as Descontinuidades Tecnológicas}

No processo atual, buscamos reestruturar as bases de dados digitais adaptados ao sistema LINUX. Tal procedimento nos permite o tratamento documental da memória coletiva no mundo urbano contemporâneo agora gerenciado pelo sistema Conectiva Linux. A intenção é permitir a ampliação do resgate de informações sobre os conjuntos documentais reunidos pelo BIEV sobre a memória coletiva e o patrimônio etnológico na cidade de Porto Alegre, não só na internet, mas a partir da instalação de dois terminais em locais préfixados, tomados aqui como topos significativo da possibilidade de recriação de tradições urbanas, onde os porto-alegrenses poderão apoderar-se de um acervo de documentos, antigos e recentes, sobre a cidade onde moram.

Partindo de coleções etnográficas sobre o mundo urbano contemporâneo porto-alegrense, a criação de terminais de consulta através do sistema de software livre significa a possibilidade futura de se ampliar gradativamente suas ferramentas, a ponto deste sistema permitir a reunião de diferentes acervos digitais (por exemplo, de instituições de pesquisa, centros de documentação, arquivos históricos etc. conveniados entre si) que poderiam ser disponibilizados, sob forma integrada.

\section{Redefinindo Antigos Procedimentos e Rotinas}

O processo de migração do BIEV para o sistema de software livre implica uma revisão geral não apenas aos manuais de orientação já consolidados como normas e procedimentos de atuação de cada Grupo de Trabalho do BIEV.

Estamos processando uma revisão geral nos procedimentos técnicos de tratamento da imagem no interior da própria produção do Banco de Imagens no sentido de adotaremse novas condutas e rotinas para o acervo de coleções etnográficas na sua base de dados tanto no posto fixo (BIEV-data) quanto na internet (BIEV-site)

A reestruturação do sistema de arquivos que configuram a base de dados digitais do BIEV significa a abertura de seu acervo documental a interatividade com os seus usuários, potencializando o caráter de democratização que caracterizaria um espaço museal virtual, disponibilizado via Internet. 


\section{Software Livre e as Possibilidades de I nclusão Digital no Gerenciamento de Memórias}

Por ser um software livre, o LINUX permitirá a participação dos usuários, no caso dos habitantes de Porto Alegre, no processo de registro documental da memória coletiva de sua própria cidade, assim como permitirá aos habitantes de outras cidades brasileiras participarem da construção social da memória coletiva de uma cultura urbana no País.

Existe concretamente a possibilidade de se construir uma plataforma onde o habitante de qualquer cidade pode trazer sua contribuição sobre a vida urbana em outras metrópoles, ampliando-se a base de dados do BIEV. Este usuário poderá, inclusive, contribuir para o processo de desenvolvimento de sistemas gerenciadores de dados e de interfaces de consulta ao apontar para eventuais problemas e necessidades e permitindo o aperfeiçoamento da funcionalidade de suas ferramentas.

\section{O Tema da Ética e da Democratização}

O tema do software livre e da discussão da ética na pesquisa antropológica com novas tecnologias se faz aqui fundamental no sentido de se discutir critérios éticos de conduta para o caso da construção de um museu virtual no interior de um mercado livre de software (por oposição ao mundo corporativo dos softwares) com base o questionamento da idéia do direito autoral, do direito de patente, direito de uso de imagem etc. nos termos da construção da autoridade etnográfica no interior da produção antropológica dirigida a rede mundial de computadores.

Portanto, ao se migrar para o sistema LINUX, podemos prever a possibilidade de serem incluídas diretamente na base de dados do BIEV informações processadas pelos próprios usuários, passamos a nos confrontar sobre o lugar da curadoria e do curador no gerenciamento de acervos na WEB uma vez que podem ocorrer doações de documentos por parte dos usuários que não levem em consideração uma relação de respeito à diversidade cultural seguida pelos pesquisadores e bolsista do BIEV, ou até mesmo, o código de ética da Associação Brasileira de Antropologia.

Não cabe tentar eliminar conflitos por meio de censura a esses produtos culturais, mas de se oferecer, na própria construção de interfaces, oportunidades de reflexão dos usuários sobre os documentos etnográficos, o contexto em que seu autor a criou e como ela se relaciona com a temática em que está inserida.

Os pesquisadores do BIEV, neste caso, serão os primeiros responsáveis pela guarda de documentos relativos às suas atividades e devem certificar-se de que documentos confidenciais não estão expostos a terceiros, por um processo de seleção a respeito dos conjuntos de coleções etnográficas a serem dispostos nos terminais de consulta.

\section{Referências}

BACHELARD, Gaston. A Dialética da Duração. São Paulo: Ed. Ática, 1987.

BERGSON, Henri. Matéria e Memória: ensaio sobre a relação do corpo com o espírito. São Paulo: Martins Fontes, 1990

BIEV. Manual de Orientação. [S.I.]:GT Vídeo: 2005.

CALABRESE, Omar. A I dade Neo-Barroca. Lisboa: Ed. 70, 1987.

DURAND, Gilbert. Les structures anthropologiques de I’imaginaire. Paris: Dunod, 1984.

ECKERT, Cornelia; ROCHA, Ana Luiza Carvalho. Imagens do Tempo nos Meandros da Memória: por uma etnografia da duração. In: KOURY, Mauro (Org.). I magem e Memória: estudos em antropologia visual. Rio de Janeiro, Garamond. 2000. P. 19-39. 
ECKERT, Cornelia; ROCHA, Ana Luiza Carvalho. A Cidade, o Tempo e a Experiência de um Museu Virtual: pesquisa antropocronotopológica nas novas tecnologias. Campos: revista de antropologia social, Curitiba, n. 2, p. 33-54, 2002.

ECKERT, Cornelia; ROCHA, Ana Luiza Carvalho da. A Cidade e o Tempo. Porto Alegre: Ed. da UfRGS, 2006.

LEROI-GOURHAN, Andre. Le geste et la parole. Paris: Albin Michel, 1964. V. 1-2.

OLIVEIRA, Roberto Cardoso de. Sobre o Pensamento Antropológico. Brasília: Tempo Brasileiro, 1988.

PIAGET, J ean. Sabedoria e Ilusões da Filosofia. São Paulo: Ed. Abril, 1978.

RABINOW, Paul. Antropologia da Razão. Rio de Janeiro: Relume Dumará, 1999.

ROCHA, Ana Luiza Carvalho da. Le sanctuaire du désordre, ou l'art de savoir-vivre des doux barbares sous les Tristes Tropiques. Orientação de M. Maffesoli. Sorbonne: Université René Descartes, 1994.

ROCHA, Ana Luiza Carvalho da. Tecnologias Audiovisuais na Construção de Narrativas Etnográficas: um percurso de investigação. Campos: revista de antropologia social. n. 4, p. 113-134, 2003.

ROCHA, Ana Luiza Carvalho da. As Práticas Políticas na Escrita Antropológica, Etnografia em Hipertextos e a Produção de Conhecimento em Antropologia. Iluminuras, Porto Alegre, v. 7, n. 16, 2006. Disponível em: <http://www.biev.ufrgs.br> Acesso em: 12 jul. 2007.

ROCHA, Ana Luiza Carvalho da. A Natureza da Representação e a Produção de Conhecimento Antropológica na WEB. Iluminuras, Porto Alegre, v. 7, n. 16, 2006. Disponível em: <http://www.biev.ufrgs.br> Acesso em: 17 jul. 2007.

ROCHA, Ana Luiza Carvalho da. Coleções Etnográficas, Método de Convergência e Etnografia da Duração: um espaço de problemas. Iluminuras, Porto Alegre, v. 9, n. 21, 2008. Disponível em: <http://www.biev. ufrgs.br> Acesso em: 17 jul. 2007.

VERGNAUD, Gerárd. Invariantes Quantitativos, Qualitativos e Relacionais. [S.I.: s.n., [1977]. Disponível em: <www.caxias.rs.gov.br/novo_site/_uploads/educacao/artigo_33.pdf> Acesso em: 11 out. 2007.

Recebido em julho de 2008

Aprovado para publicação em agosto de 2008

\section{Cornelia Eckert}

Programa de Pós Graduação em Antropologia Social da Universidade Federal do Rio Grande do Sul (IFCH/ILEA/UFRGS) chicaeckert@gmail.com

\section{Ana Luiza Carvalho da Rocha}

Programa de Pós Graduação em Antropologia Social da Universidade Federal do Rio Grande do Sul (IFCH/ILEA/UFRGS) miriabilis@gmail.com 